\title{
Commentary: The power of the pen-cardiac surgical opioid use in the United States
}

Kevin P. Landolfo, MD, MSc, ${ }^{a}$ and Archer Kilbourne Martin, MD $^{\mathrm{b}}$

\footnotetext{
From the ${ }^{\mathrm{a} D e p a r t m e n t}$ of Cardiothoracic Surgery and ${ }^{\mathrm{b}}$ Division of Cardiovascular and Thoracic Anesthesiology, Mayo Clinic, Jacksonville, Fla.

Disclosures: Authors have nothing to disclose with regard to commercial support.

Received for publication Sept 17, 2019; revisions received Sept 17, 2019; accepted for publication Sept 18, 2019; available ahead of print Oct 3, 2019.

Address for reprints: Kevin P. Landolfo, MD, MSc, 4500 San Pablo Rd, Jacksonville, FL 32256 (E-mail: Landolfo.Kevin@mayo.edu).

J Thorac Cardiovasc Surg 2020;160:964-5

$0022-5223 / \$ 36.00$

Copyright $(2019$ by The American Association for Thoracic Surgery

https://doi.org/10.1016/j.jtcvs.2019.09.102
}

The opioid crisis in the United States is a well-recognized public health problem, with opioid overdose continuing to rise at alarming rates. ${ }^{1}$ Of particular importance, the administration of opioids to surgical patients has become an important stimulus for chronic opioid abuse even among those who are opioid-naive before surgery. ${ }^{2}$ Approximately 51 million Americans undergo inpatient surgery annually, with opioids remaining a primary modality for acute pain management in the perioperative setting. ${ }^{3}$ Because no guidelines currently exist for postoperative pain management, significant variability and excessive opioid prescribing occurs given "the power of the pen" in opioid prescription writing. With regard to cardiac surgery, the risk of developing chronic opioid use in previously naïve patients has not been well studied.

In the current issue of the Journal, Clement and colleagues ${ }^{4}$ obtained insurance claim data from 7292-opioid naive patients undergoing cardiac surgery (CABG) in the United States from 2014 to 2016 (Truven Health MarketScan Database). This study is the largest published dataset analysis of opioid use in cardiac surgical patients. The authors report that the majority of the patients (77\%) filled opioid prescriptions in the perioperative period. Most notably, a staggering $8.1 \%$ of opioid-naïve patients developed new, persistent opioid use following CABG (defined as opioid prescriptions filled beyond 90 days postoperatively).

Using multivariable logistic regression, patient-specific variables that were independently associated with persistent opioid use included female sex, previous substance abuse, anxiety, chronic obstructive pulmonary disease, and geographic predilection to the southern United States. In addition, specific prescribing practices were also found to be independent risk factors for persistent opioid use. Increasing total dosages of opioids administered in the postoperative period led to greater persistent use in opioid-naïve patients. For example, for every 13 additional oxycodone tablets $(5 \mathrm{mg})$ prescribed, there was a $17 \%$

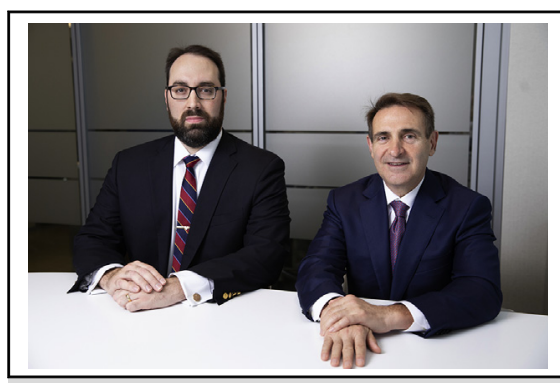

Archer Kilbourne Martin, MD (leff), and Kevin P. Landolfo, MD, MSc (right)

Central Message

The risk of developing chronic opioid use in the previously opioid-naïve cardiac surgical patient is significant. Increased awareness and multidisciplinary approaches must be developed.

See Article page 954 increased risk of persistent opioid use, a sobering fact considering the liberal prescribing of opioids following cardiac surgery. The findings presented in this study demand increased awareness of the opioid addiction risk following cardiac surgery as well as a mandate to develop strategies to reduce opioid use following cardiac surgery. Educational programs directed at the surgical teams, multimodality pain therapy, and regional analgesia are crucial to reduce the opioid use following cardiac surgical procedures. ${ }^{5,6}$ A recent publication in the Journal demonstrated that an enhanced recovery after cardiac surgery program (ie, ERAS) significantly reduced opioid use in the postoperative period.

While compelling, the study is not without limitations. The study is retrospective in nature and the database was limited to patients with private insurance $(38 \%$ of patients undergoing CABG in the United States) without including Medicare, Medicaid, or uninsured patients, which represents a selection bias potentially affecting opioid-use patterns in the data analyzed and presented.

Overall, this important study highlights an underappreciated problem in cardiac surgical patients. As cardiac surgeons provide episodic care to patients, the specialty may be unaware of the long-term effects related to "our" opioid prescribing patterns. The manuscript draws 
attention to important issues and underscores "the power of the pen."

\section{References}

1. Rudd RA, Aleshire N, Zibell JE, Gladden M. Increases in drug and opioid overdose deaths-United States 2000-2014. MMWR Morb Mortal Wkly Rep. 2016;64:1378-82.

2. Sun EC, Darnall BD, Baker LC, Mackey S. Incidence and risk factors for chronic opioid use among opioid-naive patients in the postoperative period. JAMA Int Med. 2016;176:1286-93.

3. Wunsch H, Wijeysundera DN, Passarella MA, Neuman MD. Opioids prescribed after low-risk surgical procedures in the United States, 2004-2012. JAMA. 2016;315:711-27.
4. Clement KC, Canner JK, Lawton JS, Whitman GJR, GrantMC, Sussman MS Predictors of new persistent opioid use after coronary artery bypass grafting. J Thorac Cardiovasc Surg. 2020;160:954-63.e4.

5. Rafiq S, Steinbruchel DA, Wanscher MJ, Andersen LW, Navne A, Lilleoer NB, et al. Multimodality analgesia versus traditional opiate based analgesia after cardiac surgery, a randomized controlled trial. J Cardiothorac Surg. 2014; 9:52-9.

6. Mazeffi M, Khelemsky Y. Poststernotomy pain: a clinical review. J Cardiothorad Vasc Anesth. 2011;25:1163-78.

7. Williams JB, McConnell G, Allender JE, Woltz P, Kane K, Smith PK, et al One-year results from the first US-based enhanced recovery after cardiac surgery (ERAS) program. J Thorac Cardiovasc Surg. 2019;157:1881-8. 